Research Article

\title{
A Theoretical Analysis Method of Spatial Analytic Geometry and Mathematics under Digital Twins
}

\author{
Kaiqi Wang \\ Nanjing Foreign Language School, Nanjing, Jingsu 210008, China \\ Correspondence should be addressed to Kaiqi Wang; sherlockholmes2021@163.com
}

Received 19 October 2021; Revised 10 November 2021; Accepted 24 November 2021; Published 9 December 2021

Academic Editor: Zhihan Lv

Copyright ( 2021 Kaiqi Wang. This is an open access article distributed under the Creative Commons Attribution License, which permits unrestricted use, distribution, and reproduction in any medium, provided the original work is properly cited.

\begin{abstract}
In recent years, online education in China has made considerable achievements. But there are also some problems: the teaching quality of online education is unsatisfactory; students' online learning effects are frustrating, and students' autonomous learning ability is poor. Based on analysis, teachers' literacy and Internet technology are important factors restricting the online teaching reform, and online teaching easily falls into the dilemma of "shallow learning." Digital twins can effectively realize the intelligent interconnection and interaction of the physical world and the information world, optimize the remote teaching process, and provide high-quality remote learning experience for learners. Based on this, the technology is used to the teaching of space geometry to help students understand it and improve their performance. First, the principle and advantages of digital twins are expounded. Second, the platform system based on digital twins is constructed. Then, the corresponding digital model is drawn by using the drawing function of MATLAB software, and the system based on virtual reality (VR) is established. Finally, the students of four classes of the same major are selected as the research subjects to test the teaching effect of advanced mathematics on the digital platform. The results show that students' scores in the traditional classrooms are form 2.5 to 5.5 and their average score is 4.049 , while the scores of the students in the digital twin classrooms are between 5.5 and 9.5 and their average score goes up to 7.986. This shows that students' performance in the digital twin classrooms is $97.2 \%$, higher than that in the traditional classrooms. A fully digitized spatial geometric model is implemented by using digital twins, and it can help students understand the mathematical theory of spatial analytic geometry, and their learning effect is greatly improved. This study provides a new direction for the application of new technologies in mathematics teaching.
\end{abstract}

\section{Introduction}

In the section of "spatial analytic geometry" of advanced mathematics, a large number of spatial graphics are required. If the lecturer just draws some graphs on the blackboard, it is difficult for students to understand them due to the poor intuitiveness of the graphics when some complex spatial geometric graphics are involved, affecting the teaching effect.

A digital twin is a simulation technology that applies multiple technologies to many disciplines, including a variety of physical quantities and scales. It applies physical models, various kinds of sensors, and the previous model to map the physical model image into the virtual space to construct a digital model. Thus, the whole manufacturing cycle of digital equipment which fully corresponds to the physical model and reflects the characteristics of the physical model is obtained. The concept of digital twins has been separated from the traditional realistic environment, and it is a digital platform system composed of one or more interconnected and cooperative system modules [1-3].

The application of emerging computer technology is studied by many scholars in China and foreign countries. Qi and Tao (2018) sorted out the big data of the manufacturing industry by using digital twins, including their concepts and applications in product design, production planning, manufacturing and predictive maintenance, and the application fields to new industries. On this basis, they compared the similarities and differences 
between big data and digital twins [4]. Zhuang et al. (2018) proposed a framework of intelligent production management and control methods for complex product assembly workshops based on digital twins, and three core technologies are established: real-time acquisition and management of physical data in assembly workshops, the use of digital twins to construct relevant digital models for product assembly, and the use of big data and digital twins for auxiliary work [5]. Lv (2019) proposed a comprehensive technology according to the relevant achievements to realize the human-computer interaction of the Internet of Things (IoT) naturally and intelligently [6]. Skobelev et al. (2020) established an intelligent information physics system based on digital twins to manage agriculture and proposed a calculation method of plant growth period prediction and yield prediction. And then a "tube" model of parameter change in each stage of plants is established. A method for calculating yield prediction is also introduced, as well as the method for calculating the start and end dates of each stage [7]. Lopez et al. (2020) developed a hybrid soft sensor to monitor and predict the evolution of cellulosic ethanol fermentation. This combination of real-time data and the high-fidelity kinetic model is realized by digital twins [8]. Chen et al. (2020) established a evaluation model for teachers' ability and a data acquisition model for teachers' professional ability based on machine learning and digital twins. They also fused the data collected by the two models, and the fusion includes data cleaning and integration, data screening, and clustering strategy screening [9]. Wu et al. proposed a new method called "RegARD." First, RegARD is used to detect the symmetry reflected by buildings to constrain rotation and reduce degrees of freedom. Second, the nonlinear optimization equation and advanced optimization algorithm are used to solve the quadratic optimization [10]. In short, digital twins are mainly applied to mold manufacturing in various intelligent manufacturing environments, or to the evaluation of the teaching level of lecturers. The studies on the application of digital twins to subject teaching, especially to mathematics teaching, are few, which is also the innovation of this article. The analysis method of the mathematical theory of spatial analytic geometry based on digital twins is studied. This provides a reference for the application of emerging computer technology to mathematics teaching.

Nowadays, various new computer technologies emerge one after another. Here, digital twins are studied and used to improve the traditional teaching method of advanced mathematics, and the digital twin podium system is constructed, making the digital model of the teaching model and providing an overall spatial map. The standardized teaching process is proposed. The study makes a prominent contribution to applying digital twins to the teaching of solid geometry in colleges and universities. First, the principle and advantages of digital twins are expounded and the platform based on digital twins is constructed. Second, the corresponding digital model is drawn by the drawing function of MATLAB software, and the system under virtual reality (VR) is constructed. Finally, the learning effect of advanced mathematics on digital twin platform is tested. The results show that the teaching effect is greatly improved, and the students' ability to understand spatial analytic geometry is also enhanced. The innovation is that the teaching mode and the teaching classroom of space geometry are constructed based on digital twins. The practicability and effectiveness of the teaching mode proposed are proved by examples.

\section{Construction of the Teaching System of the Spatial Analytic Geometry Theory}

2.1. Internet of Things (IoT). IoT is born at MIT (Massachusetts Institute of Technology) in 1999. It is a new information service architecture based on Internet and identification technology and communication technology [11]. The objective of establishing this architecture is to enable the information technology infrastructure to provide safe and reliable "goods" information through the Internet and create an intelligent environment to identify and determine "goods," promoting the information exchange within the supply chain. IoT develops rapidly and brings changes to human life and going deep into all aspects of human life, causing a series of technical ethics problems, security problems, and legal problems that need to be solved urgently [12]. IoT is usually deployed in four layers to the consumer side: the device domain, the network domain, the data domain, and the application domain, which gives the device the means to intelligently perceive the surrounding environment, automatically assemble connection and deployment strategies, solve the problems in data centralization, provide users with some help, and give the device simple processing ability. With the arrival of the second decade of the 21 st century, various traditional information technologies begin to combine with IoT to create new means to serve human society [13]. IoT architecture and its application fields are shown in Figures 1 and 2, respectively.

\subsection{Digital Twins Podium}

2.2.1. Digital Twins. All companies are actively promoting digital transformation to trigger the core value of the industrial Internet. A large number of "physical entities" are merging with "digital virtual institutions," which is commonly known as "digital twins." In 2002, Professor Dr. Michael Grieves of the University of Michigan put forward the concept of digital twins for the first time in an article. In the Technical White Paper in 2013, the U.S. military called the digital thread [14] and the digital twins as an important force to change the future war situation. The U.S. military believes that using this physical level data can create a set of digital projections corresponding to the physical object of the physical space in the virtual information space, and this projection includes various equipment modules, which are dynamically linked together and always coordinated in the whole life cycle of products. 


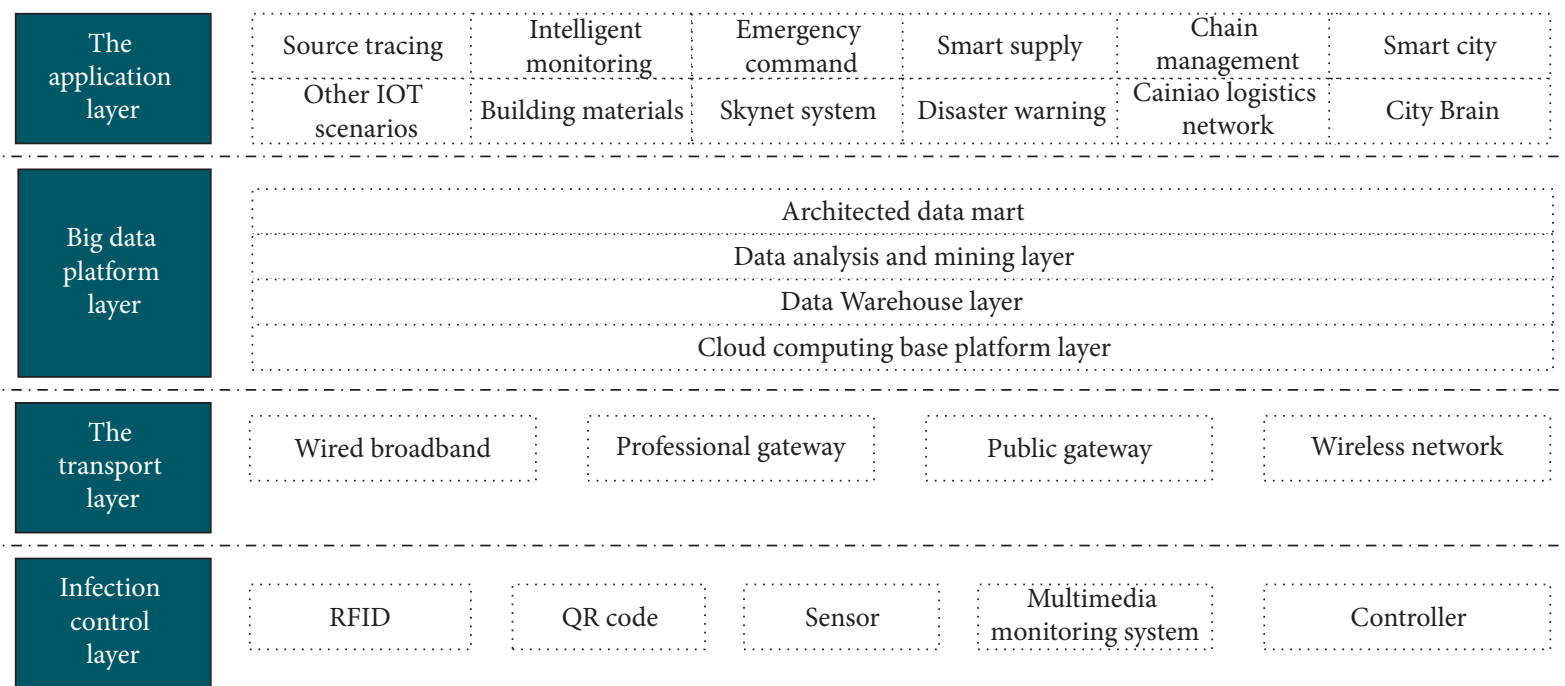

FIGURE 1: IoT architecture.

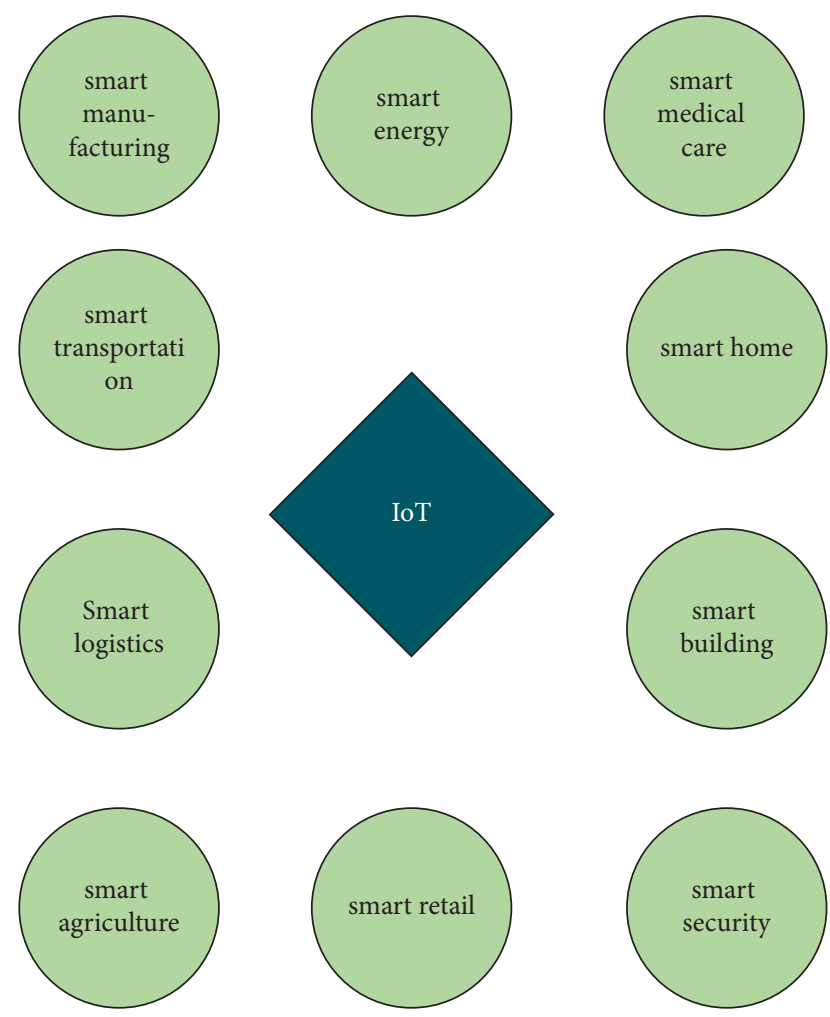

Figure 2: Application fields of IoT.

Since then, the application field of digital twins is expanding, and a series of applications such as analog simulation, virtual assembly, and 3D printing are developed. After 2014, AI is applied to various industrial products and equipment that have not been used before with the continuous development of IoT and AI (artificial intelligence), and the application of digital twins is also applied to complete production and service links. Moreover, digital twins no longer only refer to the technology applied in the product design stage but are fully extended to the whole production process and external service links. However, digital twins are only proposed rather than applied a few years ago because computer technology is not developed [15].

Digital twins run through different stages of the life cycle of products, which perform the same function as PLM (product lifecycle management) [16]. In other words, digital twins really apply the original route of product lifecycle management to the whole production process. Digital twins take the product as fundamental and add various other modules in each period of the whole life cycle to meet different needs. Figure 3 shows the operation process of digital twins.

2.2.2. Application Field of Digital Twins. Application of digital twins to the design stage: digital twins are applied to making digital models to simulate and test the performance of their manufactured products. The main functions of the technology applied at this stage are as follows: (a) digital model design: the computer-aided design (CAD) drawing software is used to construct a digital model that meets the predetermined requirements, accurately expressing the real physical parameter performance of the product and constructing a visual model in digital form so that a large number of technical means can be used to verify and adjust the accuracy of the original model; (b) simulation: a large number of reproducible and variable parameter simulation model tests are used to test the performance of the constructed product model under various actual conditions, achieving the purpose of the performance test in the design link [17].

Application of digital twins to the manufacturing stage: digital twins are used for simulation, which can significantly shorten the time required for offline products, and are very effective for product quality assurance and reduce production costs. The technology used in the production stage requires high coordination of various production modules. The virtual production line is built with computer technology to achieve the integration of production modules and processes, and finally realize the 


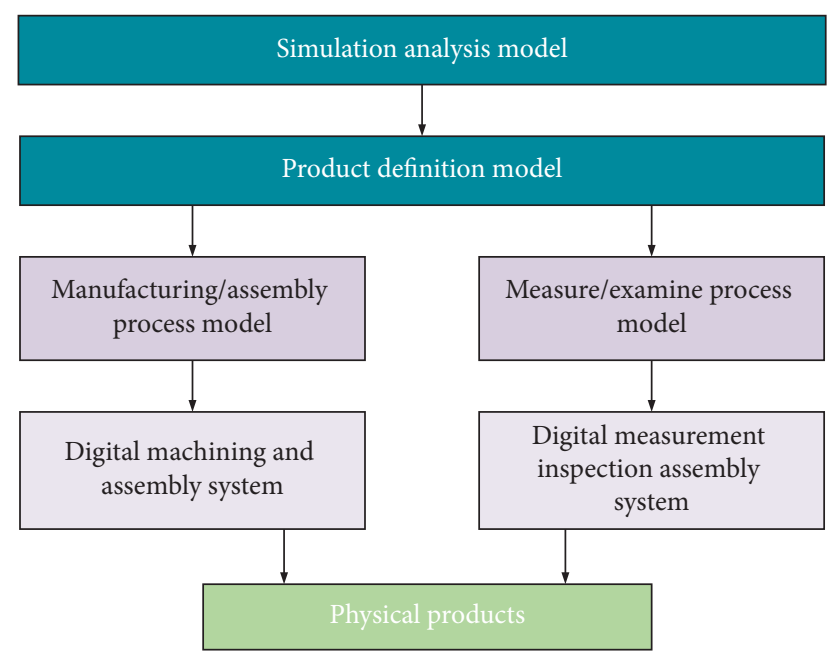

FIgURE 3: Operation process of digital twins.

simulation of the production process. Before product production, the simulation of the whole production process and products with different performance can be realized. Finally, the prediction of the production process and possible product problems is achieved, shortening the time of offline products [18].

Application of digital twins to the service stage: due to the rapid development of IoT and the popularity of various industrial sensors, many products that do not use intelligent production can use a large number of sensors in the production process to obtain a large number of parameters and performance parameters, ensuring the accuracy of the production process and the stability of product performance parameters, and finally improving product performance and increasing user's satisfaction. The application of digital twins to the service stage includes the following functions: (a) it gives early warnings in the remote monitoring and production mechanical performance; various installed sensors and production system monitoring means are used to build a visual remote monitoring system and carry out regular data maintenance and data analysis to analyze the hidden dangers of production equipment, component modular and hierarchical orderly production system; deep learning and other technologies are used to predict the trend, optimizing the production equipment maintenance plan and parts procurement plan according to the above results and reducing the loss caused by machine failure; (b) optimize customers' production indicators: equipment manufacturers can use big data for analysis and establish equipment parameter adjustment models for different actual environments to help their customers adjust equipment parameters, improving the product quality and production efficiency of downstream product manufacturers; and (c) product use feedback: realtime analysis can be carried out by using the monitoring data of the equipment to understand the real needs of downstream customers [19].
2.2.3. Digital Twins Podium. The digital twins platform is a teaching system that connects real teaching and data teaching space through the network. The relationship between virtual and reality is mapped, coordinated, and interactive one by one. That is, the digital twins podium includes virtual learning feature analysis technology and teaching space interaction technology, and they are used to improve the teaching effect and give students better learning conditions. The application of virtual learning feature analysis technology is to teach students according to their aptitude, make the lecturer's teaching plan match the specific situation of students, and pay attention to the interaction between teachers and students, realizing the accurate management of the classroom and the high efficiency of teaching. The interactive technology of teaching space refers to the use of various technical means to construct a network space containing all elements corresponding to the actual teaching space and can realize the visualization of this space, ensure real-time interaction, and construct a virtual teaching space $[20,21]$. Figure 4 shows the specific system of the digital twins podium.

The digital twins podium includes four layers: the data support layer, the modeling computation simulation layer, the function layer, and the immersive experience layer. Table 1 shows the structure of four layers of digital twins podiums.

\subsection{Graphics of Spatial Analytic Geometry}

2.3.1. Drawing Software. Matlab is the abbreviation of Matrix Laboratory [22, 23]. It is made by American commercial companies. This software is mainly used for mathematical analysis. Its functions include algorithm development, data analysis, computer language numerical simulation, and human-computer interaction. Its function of drawing functions/data images is used in the study. 


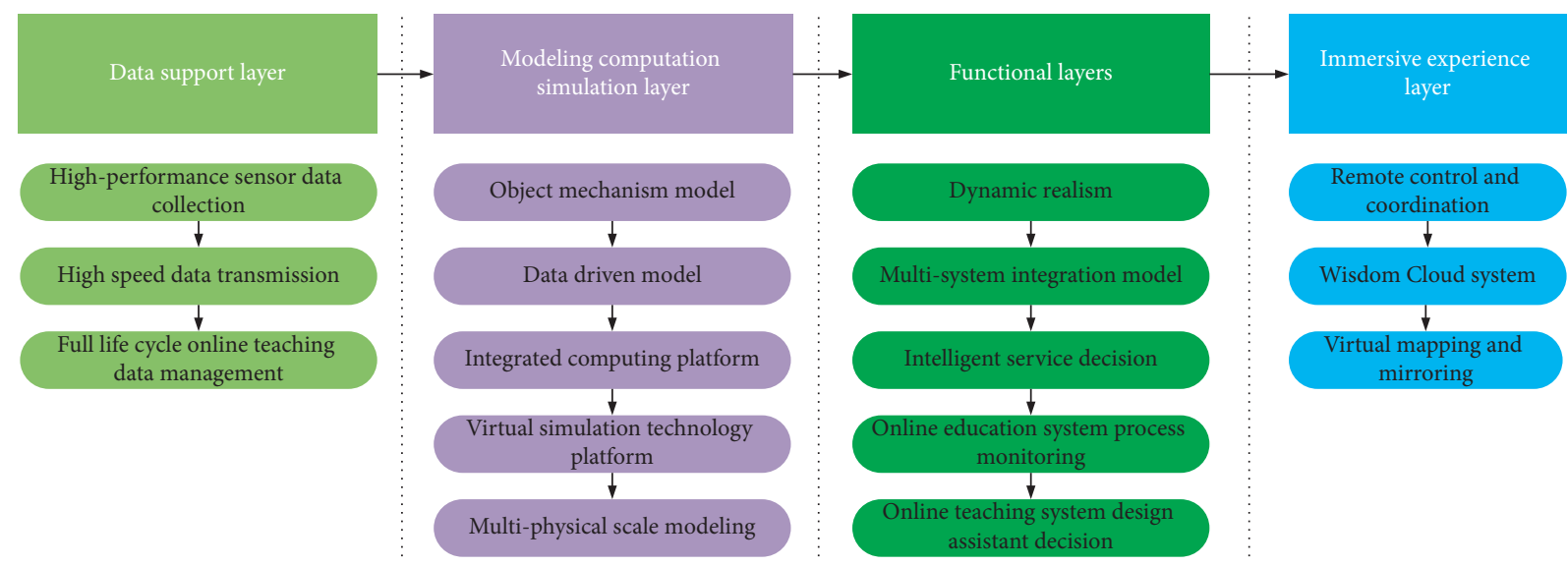

FIgure 4: System of digital twins podium.

TABle 1: Hierarchy of digital twins podium.

\begin{tabular}{|c|c|c|c|}
\hline Number & Name & Function & Composition \\
\hline 1 & Data support layer & $\begin{array}{l}\text { Because the construction of a digital twins podium } \\
\text { needs the interaction and IoT perception between } \\
\text { real and virtual space, the data layer is built and all } \\
\text { kinds of sensors and technical equipment are used to } \\
\text { collect information and realize the accurate mapping } \\
\text { between the two spaces. This can achieve a } \\
\text { comprehensive, three-dimensional, and profound } \\
\text { collection of classroom situations. }\end{array}$ & $\begin{array}{l}\text { High-performance sensor data acquisition, high- } \\
\text { speed data transmission, life cycle online teaching } \\
\text { data management }\end{array}$ \\
\hline 2 & $\begin{array}{c}\text { Modeling } \\
\text { computation } \\
\text { simulation layer }\end{array}$ & $\begin{array}{l}\text { It is mainly used in simulation experiments. The } \\
\text { establishment of the virtual model involves all- } \\
\text { around compound modeling, that is, it is necessary to } \\
\text { model the teaching process in real space from } \\
\text { different fields and basic principles. The focus of this } \\
\text { process is data analysis, which is the perfect } \\
\text { combination of virtual and reality. }\end{array}$ & $\begin{array}{l}\text { Modeling algorithm, integrated computing } \\
\text { platform, virtual simulation technology platform }\end{array}$ \\
\hline 3 & Functional layer & $\begin{array}{l}\text { First, reality and the online teaching process need to } \\
\text { be the same in all aspects, and can accurately and } \\
\text { dynamically simulate the real process. Second, the } \\
\text { simulation results of a large number of models need } \\
\text { to be comprehensively summarized and integrated, } \\
\text { which is also the main advantage of the digital twins } \\
\text { system. The third is to use a series of data } \\
\text { visualization transformations to map the real } \\
\text { operation scene to the online virtual space in a } \\
\text { multidimensional and dynamic way, simulating the } \\
\text { actual (e.g. smart logistics scene) and virtual } \\
\text { interaction. }\end{array}$ & $\begin{array}{l}\text { Virtual teaching space and its mapped real } \\
\text { teaching space, multiscale and integrated } \\
\text { description of students' learning state and } \\
\text { environment, realizing the dynamic, visual and } \\
\text { realistic operation scene of students' online } \\
\text { learning state and environment }\end{array}$ \\
\hline
\end{tabular}


TABLE 1: Continued.

\begin{tabular}{cc}
\hline Number Name & Function \\
\hline & First, teachers use big data visualization, AI (artificial \\
intelligence), and intelligent cloud systems to present \\
the full picture of the actual teaching space in detail. \\
Second, students can immerse themselves in the \\
process of students' learning and development based \\
on the intelligent cloud system through remote \\
cooperation. Third, teachers use detailed data \\
modeling, simulation, visualization, and other \\
technologies to realize highly expressive operation \\
scenes, and present virtual learning places in an all- \\
round way without boundaries through augmented \\
reality technology; the learning environment is based \\
on real technology and remote control, which makes \\
students highly interactive. Combined with the "big \\
data + AI" platform and analysis software, the \\
mapping and mirroring of real application scenes are \\
digitally controlled in the virtual learning space, the \\
digital and seamless communication and interaction \\
between teachers and students are felt, and their \\
virtual control virtual reality and practicality are used \\
to achieve the goal of innovative learning and \\
educational activities based on digital twins platform.
\end{tabular}

2.3.2. Drawing with Matlab Drawing Function. The Mesh grid function in Matlab is used to draw spatial geometry. First, the equation of spatial graphics is provided, and it can be in the form of the parametric equation, polar coordinate equation, general equation, spherical coordinate equation, cylindrical coordinate equation, and so on. Then, the number of grids needed to draw the graphics is determined, and plot3, surf, and mesh are used to draw the spatial geometry. Matlab has a function view that can observe spatial geometry from different angles. The view $(0,0)$ can be set as the front view, view $(90,0)$ as a side view, view $(0,90)$ as top view, and $(\mathrm{x}, y, z)$ point as an observation point. When spatial geometry is drawn, the outside of the surface can be set to a transparent state. The alpha function in the software can achieve this effect. $\mathrm{H}$ in alpah $(h)$ is the transparency and it is between 0 and 1 , where 0 is the fully transparent state and 1 bit is the fully opaque state.

\subsection{Virtual Reality Technology and Teaching Equipment}

2.4.1. VR (Virtual Reality) Technology. VR is first proposed in the United States around 1980. It is a comprehensive technology integrating computer technology, sensor technology, human psychology, and physiology. It simulates the external environment by using a computer simulation system. The main simulation objects include the environment, skills, sensing equipment, and perception and provide users with multi-information, three-dimensional dynamic, and interactive simulation experience. So far, it has been combined with IoT $[24,25]$.

VR has three main characteristics: immersion, interactivity, and imagination. Immersion means that the simulated environment created by the computer is very similar to reality, which makes the user think the scene is real, and then carry out real interactive activities in this environment. Interactivity means that users can manipulate and respond to objects in the virtual world. For example, in the virtual world, users can perceive objects with their hands and eyes. Eyes can perceive the shape of objects, and hands can perceive the weight of objects and can process objects independently. Mobile imagination means that the virtual world broadens people's imagination in the real world. It can not only imagine the real existence of the real world but also imagine the existence or nonexistence of the real world. The application of this technology can greatly improve the students' research on the theoretical analysis methods of spatial analytic geometry and mathematics.

2.4.2. Student Learning Equipment. During the teaching of the theoretical analysis of spatial analytic geometry and mathematics, students need to use HTC VIVE wearable equipment with two handles and a VR helmet, as shown in Figure 5. HTC VIVE is developed using a unity development engine and network communication technology based on Network View.

The built-in system of HTC VIVE is developed with a unity engine. Computer configuration for development: GTX2080 for the graphics card, Intel i7-7300 for CPU, HDMI 1.4 for video output, windows 10 for the operating system, and C\#.

2.5. Mixed Teaching and Management Platform. This platform enables the learning and practice resources in the teaching process to be allocated according to the teaching needs, and the language points and skill points in the current learning resources are fragmented. It is convenient for teachers to use in the classroom and students to study 


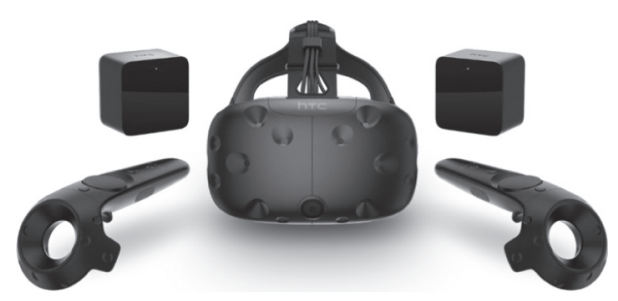

FIgURe 5: HTC VIVE wearable device.

independently after class [26-28]. Figure 6 shows the modules contained in the teaching platform, and Table 2 shows the overview of the functions of the platform.

\subsection{Analysis of the Teaching Process of Spatial Analytic} Geometry. Figure 7 shows the overall flow chart.

Figure 7 shows the online immersion teaching system based on digital twins, which includes three parts: (1) teaching data collection and management based on hybrid platform; (2) teaching data analysis and modeling based on multidimensional analysis; and (3) online immersive teaching experience based on augmented reality technology.

Figure 8 shows the data acquisition and management.

Figure 8 shows the teaching data acquisition and management on the hybrid platform using image acquisition and recognition technology. Multiple technologies are used to collect students' features during online learning, and image data acquisition is completed by camera and facial expression, as well as their limb behavior recognition. Here, students are required to open the camera in Tencent Classroom, and mobile phones take the photos of students regularly in front of the camera. The convolutional neural network (CNN) in deep learning is used to recognize the facial expressions and behaviors of students, and then classify them.

Figure 9 shows the application data based on precision teaching and management.

Figure 9 shows the analysis and modeling of teaching data, and the teaching process and materials can be visualized in multiple dimensions. The teaching materials include electronic teaching materials, electronic lesson plans, and courseware.

Figure 10 shows the teaching experience of the augmented reality technology.

Figure 10 shows the online immersive teaching experience based on augmented reality technology, which mainly includes the interaction and integration of real and virtual teaching space. The digital virtual scene is constructed by using big data and artificial intelligence. In terms of integration and innovation, a variety of technologies are used, including 3D modeling, big data modeling, big data simulation, big data visualization, and virtual reality technology.

Digital twins are used to build a digital twins platform, and the augmented reality technology is used to assist in teaching so that students can learn the theory of analytic geometry and mathematics in three-dimensional space in the virtual reality environment. The teaching process of this system includes (a) a hybrid platform is used for teaching data collection and management, and multiplatform and multisource data are used for data collection; (b) the system is used for accurate teaching data management, the teaching through multidimensional, dynamic, and visual process, and teaching material collection and teaching process; and (c) the constructed system is used for teaching on the VR digital twins platform, and the digital virtual system constructed by the interactive system of reality and virtual teaching space is used for teaching $[29,30]$.

2.7. Matlab Program Procedures. Matlab is used to construct the surface, and the program diagram is shown in Table 3.

\section{Design of the Teaching Platform}

3.1. Case Analysis. The students in four classes of the same major of a university are randomly selected to investigate the effect of the teaching program. The teaching program based on digital twins is not carried out on the students in two classes, and the numbers of students in these two classes is 29 and 30 , respectively, named group $A$ and group $B$. The students in other two classes are taught by using the teaching program based on digital twins. The numbers of students in these two classes is 31 and 28, respectively, called group C and group D. A week later, some exercises with a certain difficulty are used for in-class test, and there are 10 questions, of which 7 are conventional questions, 2 are difficult questions, and 1 is highly difficult questions. The scores of the four classes are shown in Table 4.

Through the Matlab virtual graphics of the teaching system as shown in Figure 11 above, it is found that the effect of the graphics is good, the spatial curve can be observed from different directions, and the grid lines can depict the spatial quantitative relationship, which shows that the Matlab software is effective in describing the spatial threedimensional geometry and can be observed from multiple angles, which helps students understand the mathematical theory easily.

3.2. Comparison of the Teaching Effect. Figure 12 shows the statistical data of each student's performance in the four classes. Figure 13 shows the comparison of the teaching effects of the traditional classroom and the digital twin classroom.

Figure 12 shows that the four classes A, B, C, and D are taught in different classrooms. Classes $\mathrm{A}$ and $\mathrm{B}$ are in traditional classrooms, and classes $\mathrm{C}$ and $\mathrm{D}$ are in digital twin 


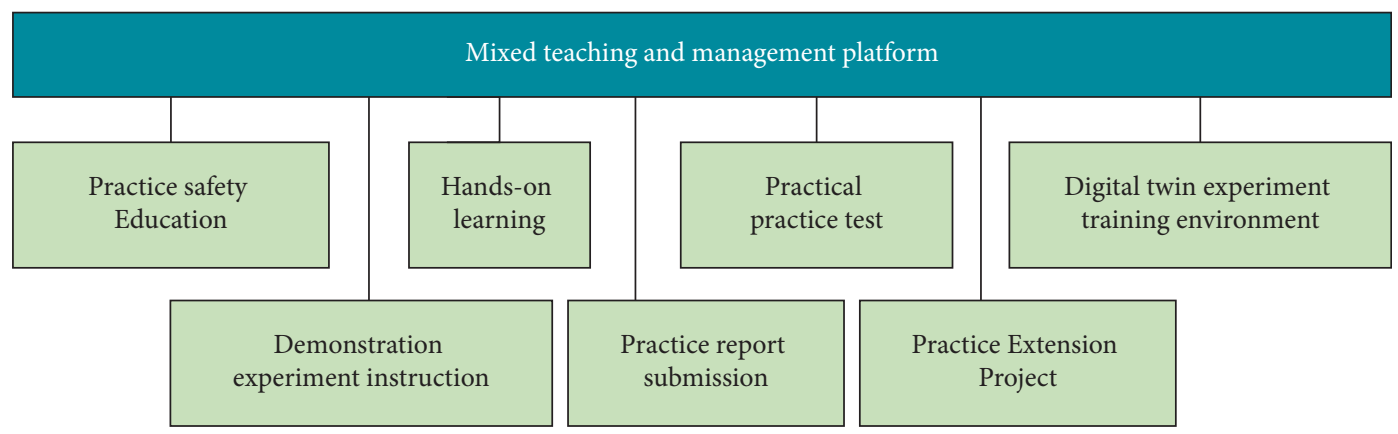

Figure 6: Modules included in the teaching platform.

TABLE 2: Overview of the functions of the platform.

Objects Functions

The platform enables students to master the learning process independently and carries out orderly learning according to their

Students plans and processes. Way of autonomous learning is used to stimulate students' enthusiasm and interest in autonomous learning, exercise their learning ability, practical ability, and innovation ability, finally forming the habit of lifelong learning.

The system should also provide teachers with relevant function settings, help release learning resources and practice resources, and guide and supervise teaching activities. Teachers use the platform to complete teaching resources before the beginning of the

Teachers course, such as course teaching, theoretical animation, reference materials and operation manuals, organization of design and teaching process, and the release of design and practice. In the teaching process, teachers use the tasks provided by the forum to guide, monitor, and evaluate students' learning progress, adjust the teaching process according to students' teaching ability, and improve students' teaching skills.

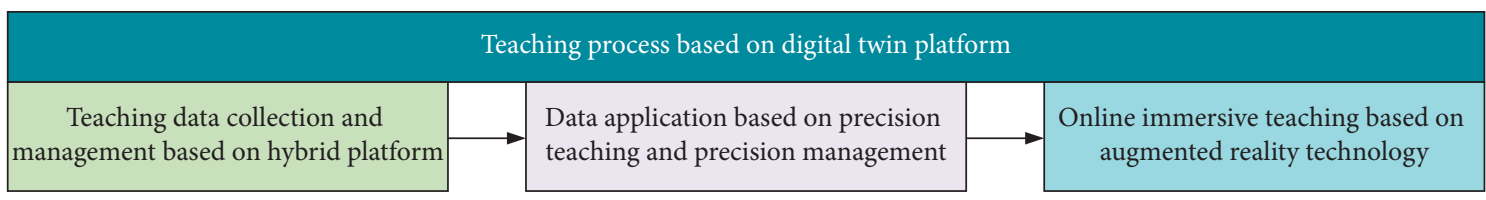

FIgURE 7: Overall flow chart.

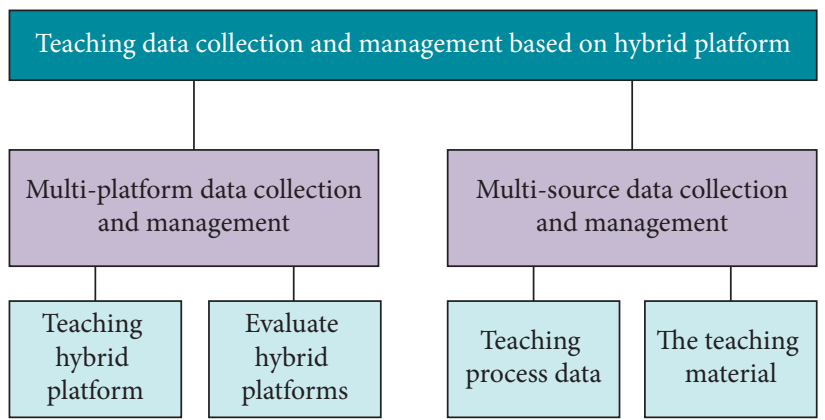

FIgURE 8: Data acquisition and the structure of the management module.

classrooms. The figure shows that there are differences in the scores of each student. The scores of the students in Classes $\mathrm{A}$ and $\mathrm{B}$ are from 2.5 to 5.5 , and those of the students in Classes C and D are between 5.5 and 9.5. Obviously, the scores of each student in Classes $\mathrm{C}$ and $\mathrm{D}$ are higher than those in other two classes. This shows that the teaching mode based on digital twins can significantly improve the performance of each student in the class. The average scores of the four classes are counted, as shown in Figure 12(e). The average scores of Classes A and B are 4.045 and 4.053 and those of Classes $\mathrm{C}$ and $\mathrm{D}$ are 7.861 and 8.111. The average score of the students in Classes C and D is 7.986, which is 97.2\% higher than that of the students in Classes A and B, indicating that the use of digital twins in mathematics teaching can significantly improve the students' performance and enhance the teaching effect.

Figure 13 shows that the average score of the students in the digital twin classrooms is higher than that of the 


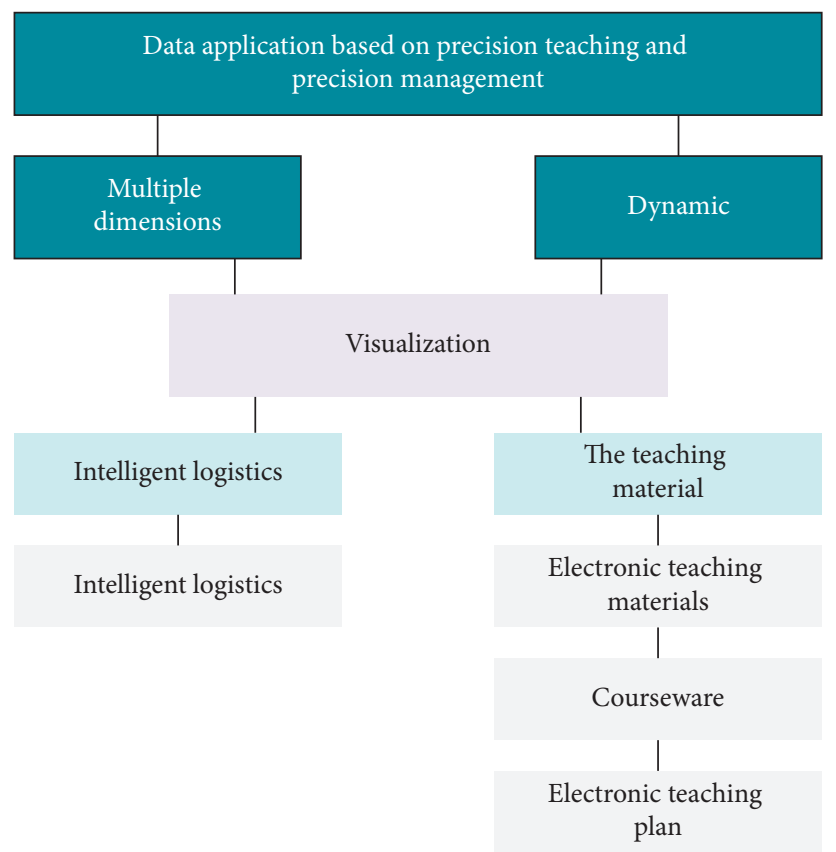

FIGURE 9: Application data of precision teaching and management.

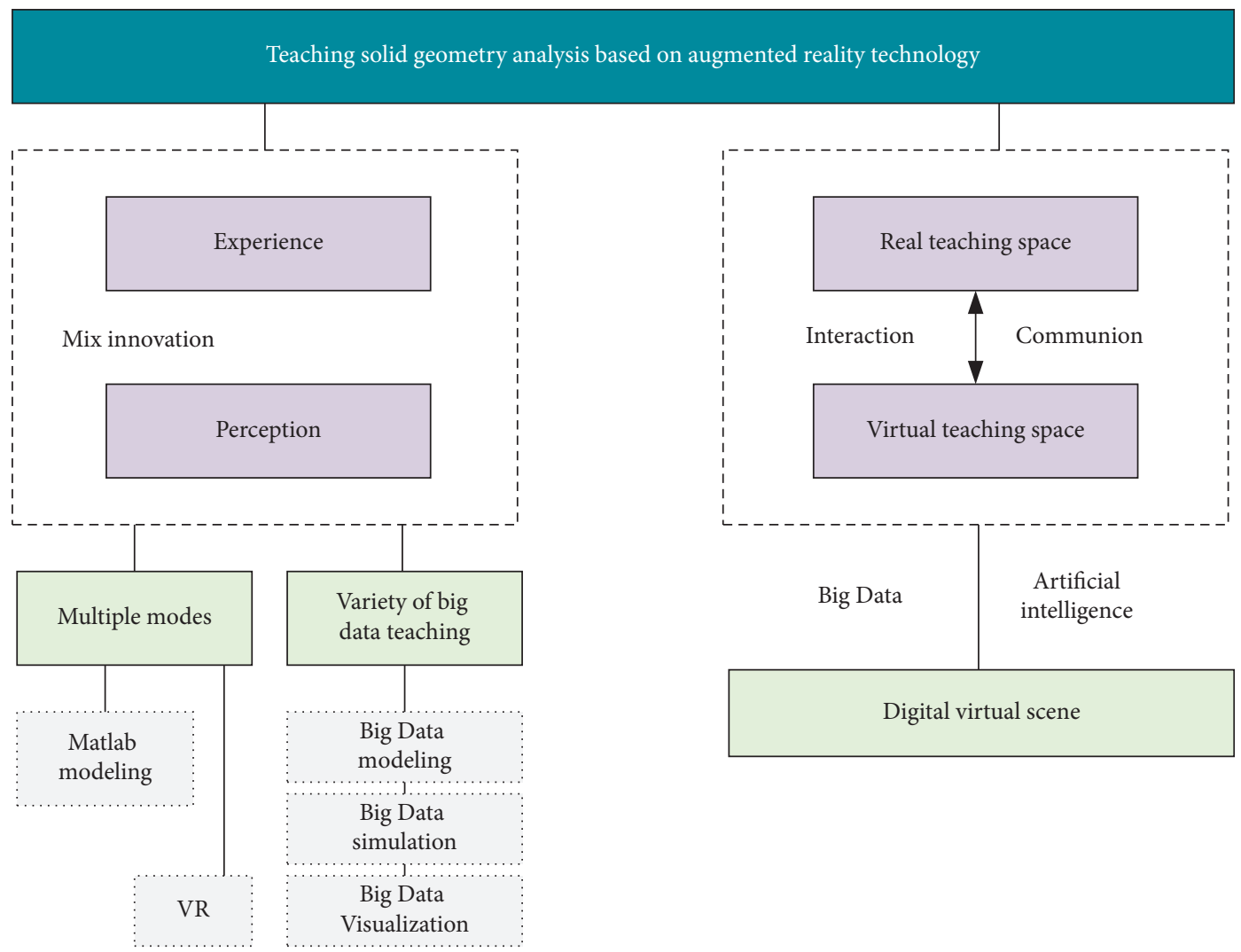

FIgURE 10: Teaching experience of the augmented reality technology.

students in the traditional classroom. The average number of correct answers in the two classes in the conventional classroom is 7.4 and 7.6, respectively, while the average number of correct answers is more than 8 for the teaching mode with digital twins platform; the average score of the students on the digital twins platform is more than that in the conventional classroom; the difference between medium and high difficulty questions 
TABLE 3: Matlab program of geometry.

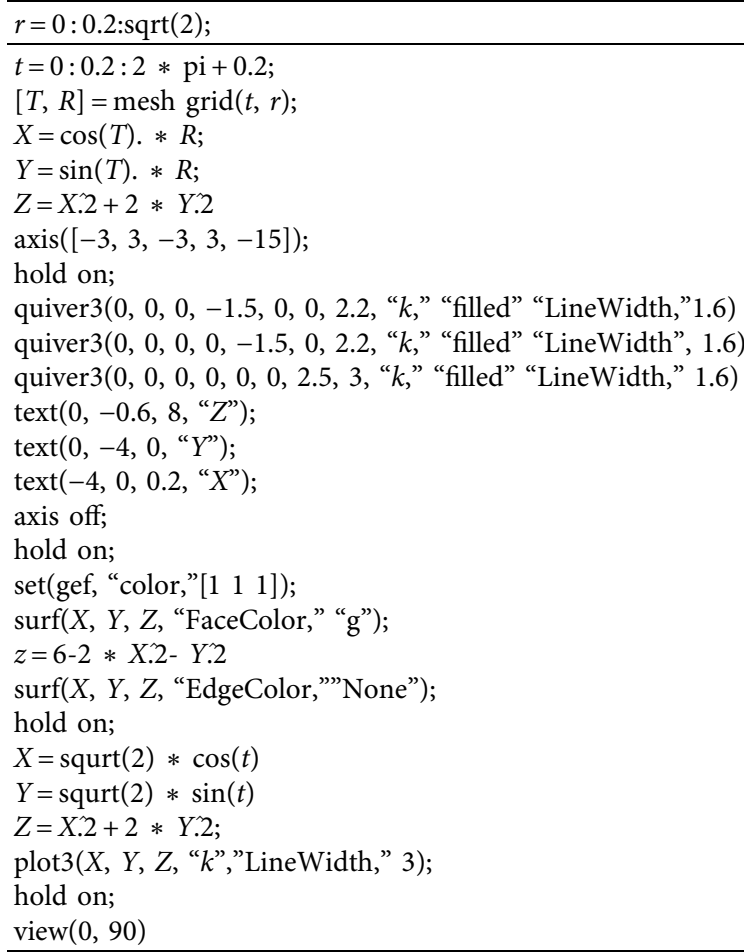

TABLE 4: Score statistics of four classes.

\begin{tabular}{|c|c|c|c|c|}
\hline Students/classes & $\mathrm{A}$ & $\mathrm{B}$ & $\mathrm{C}$ & $\mathrm{D}$ \\
\hline 1 & 2.5 & 3.3 & 7.9 & 6 \\
\hline 2 & 3.4 & 4 & 7.1 & 8.2 \\
\hline 3 & 4 & 4 & 9.4 & 8 \\
\hline 4 & 4.9 & 3.9 & 8.1 & 8.3 \\
\hline 5 & 4.6 & 3.4 & 5.6 & 7.5 \\
\hline 6 & 5 & 3.5 & 6.9 & 7.7 \\
\hline 7 & 3.6 & 3.5 & 9.9 & 8.2 \\
\hline 8 & 3 & 3.3 & 9.3 & 8.9 \\
\hline 9 & 2.5 & 5 & 6.4 & 7.5 \\
\hline 10 & 3.7 & 4.1 & 7.9 & 8.8 \\
\hline 11 & 4.9 & 4.2 & 9.3 & 8 \\
\hline 12 & 3.9 & 3.4 & 5.5 & 9.1 \\
\hline 13 & 3.8 & 3.1 & 9.6 & 9.9 \\
\hline 14 & 3.7 & 5.2 & 8.4 & 9 \\
\hline 15 & 5.3 & 2.5 & 10 & 7.4 \\
\hline 16 & 4 & 2.9 & 6.1 & 7.8 \\
\hline 17 & 3.7 & 5.1 & 6.4 & 9.3 \\
\hline 18 & 4.1 & 5.3 & 9.8 & 9.7 \\
\hline 19 & 3 & 4.4 & 6.8 & 6.2 \\
\hline 20 & 4.4 & 4.5 & 7 & 7.6 \\
\hline 21 & 5.1 & 4.4 & 7.2 & 9.6 \\
\hline 22 & 4.8 & 2.9 & 9.6 & 9.1 \\
\hline 23 & 5.4 & 5 & 7.2 & 7.6 \\
\hline 24 & 2.8 & 4.2 & 9.4 & 9.8 \\
\hline 25 & 4.6 & 5.5 & 5.9 & 9.5 \\
\hline 26 & 4.1 & 3 & 5.6 & 6.1 \\
\hline 27 & 5.1 & 3 & 9.9 & 5.5 \\
\hline 28 & 3.6 & 5.3 & 9.5 & 6.8 \\
\hline 29 & 3.8 & 5.2 & 6.6 & \\
\hline 30 & & 4.5 & 8.9 & \\
\hline 31 & & & 6.5 & \\
\hline
\end{tabular}

$z=x^{2}+2 y^{2}$ and $z=6-2 x^{2}-y^{2}$ are the three-dimensional geometries, and the program provided in Section 2.7 is used to construct the surface. Figure 11 shows the effect diagram drawn by Matlab. 


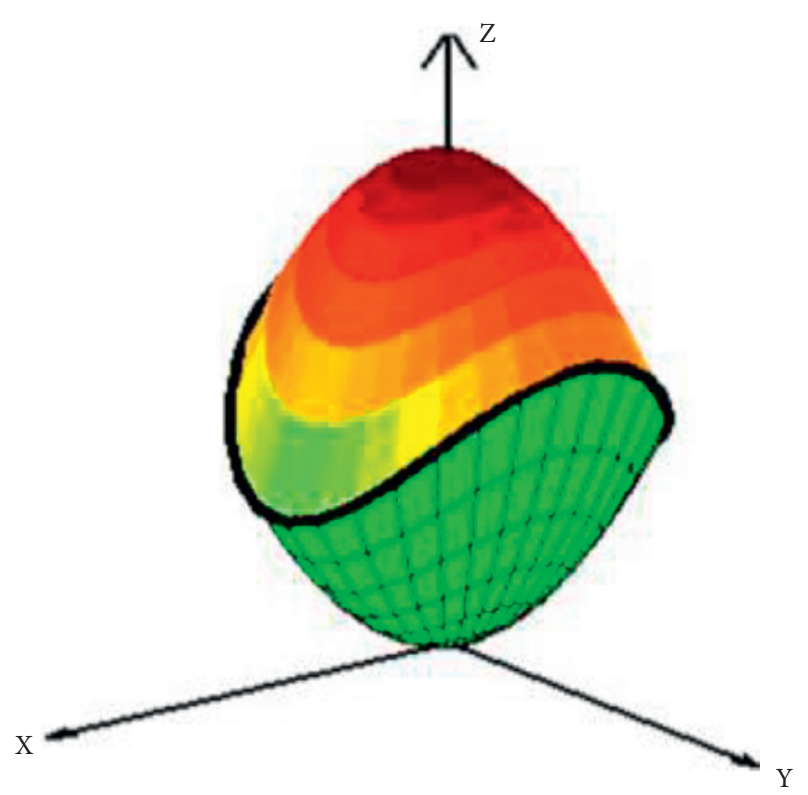

(a)

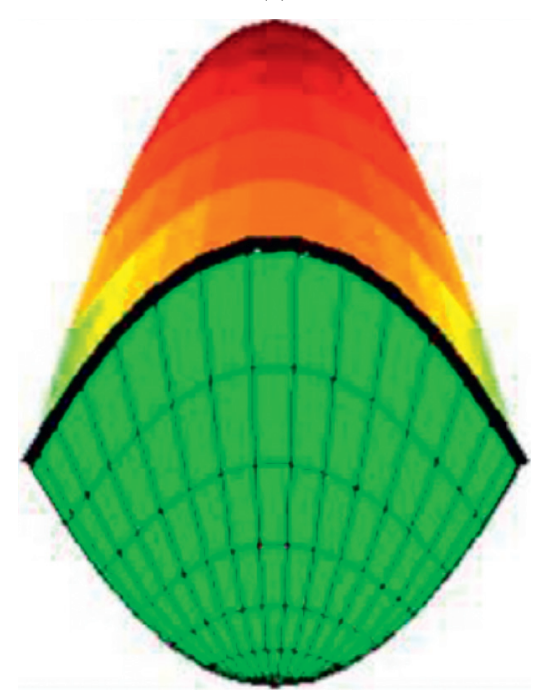

(c)

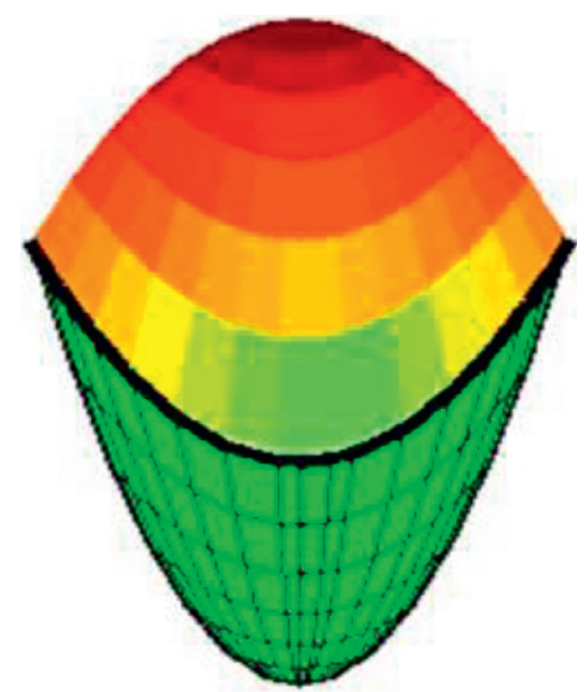

(b)

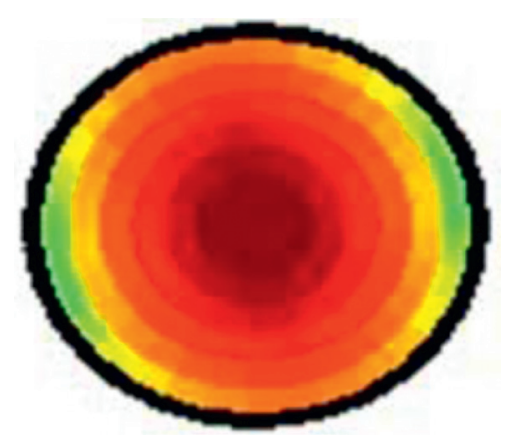

(d)

Figure 11: Actual effect graphics drawn by Matlab: (a) stereoscopic view, (b) front view, (c) side view, (d) top view.

is not great because medium and high difficulty questions are based on a complete understanding of knowledge and related to personal talents and conditions, so they have little impact. This test shows that the mathematics class with a digital twins podium is beneficial to students' understanding and can significantly accelerate students' understanding of new concepts of spatial analytic geometry. 

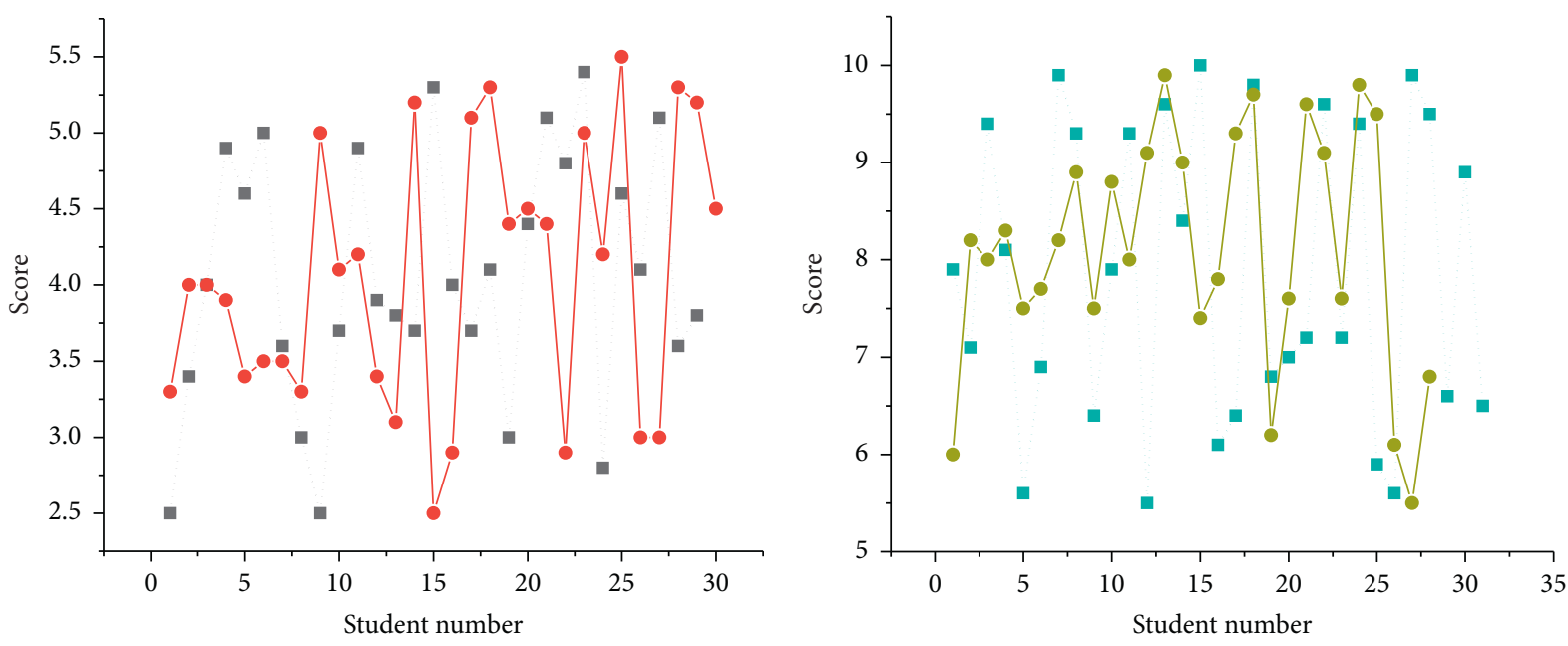

$\because \mathrm{A}$
$-\mathrm{B}$

- . C C

$\longrightarrow \mathrm{D}$

(a)

(b)

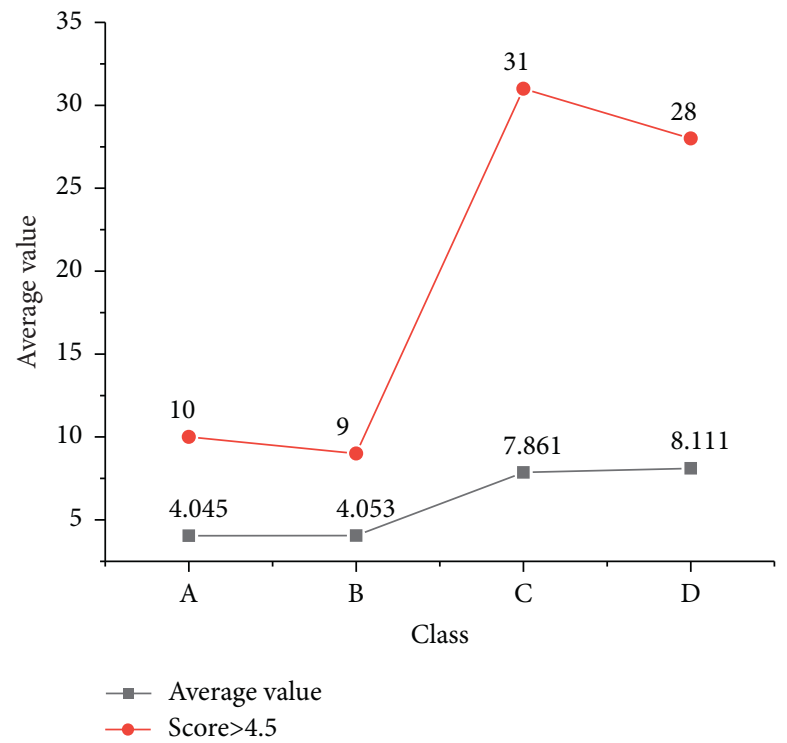

(c)

FIGURE 12: Statistics of students' scores: (a) teaching mode in the traditional classroom; (b) teaching mode in digital twin classroom; (c) average scores. 


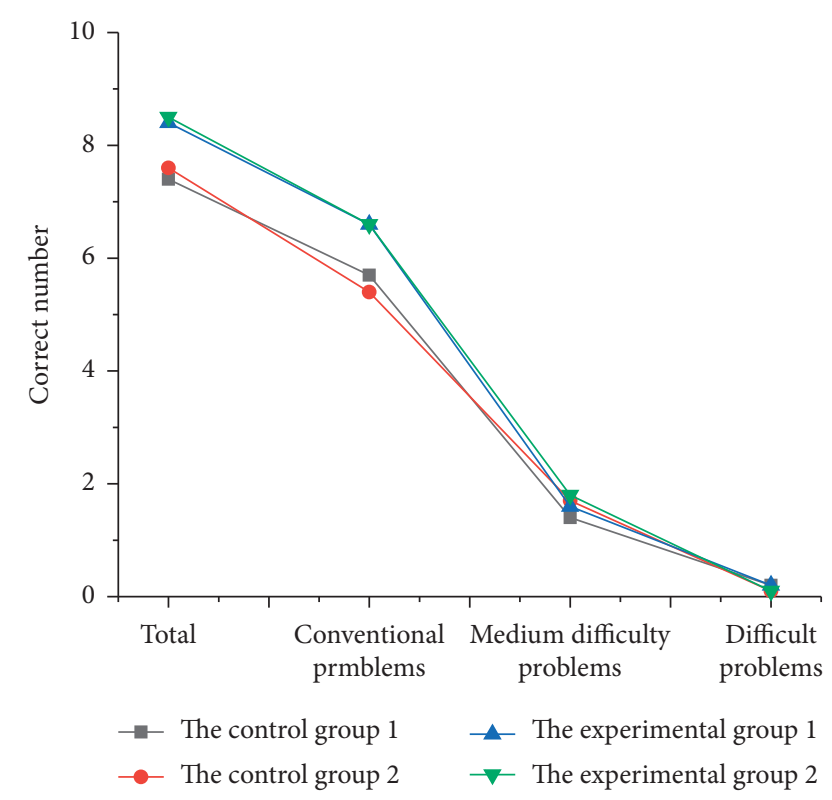

FIgURE 13: Comparison of the scores between the ordinary classroom and the classroom with digital twins podium.

\section{Conclusion}

Digital twins can effectively realize the intelligent interconnection and interaction of the physical world and the information world and optimize the remote teaching process. With the rapid development of computer and Internet technology, "big data + AI" becomes a new driving force, thinking mode and problem-solving method in modern society, and it is also used in the subject teaching nowadays. Theoretical analysis and teaching method of analytical geometry and mathematics are introduced based on digital twins. First, the principles of IoT and digital twins are expounded; second, the related digital twins platform system is constructed; furthermore, the corresponding digital model is drawn by using the drawing function of Matlab software, and it is brought into the classroom for teaching analysis by using virtual reality technology; finally, the effect of digital twins teaching of spatial analytic geometry mathematics is evaluated and tested. The results show that the digital spatial geometric model can be made by using digital twins, which is conducive to analysis and calculation, and the use of virtual reality technology can help students understand the mathematical theory of spatial analytic geometry and improve the teaching effect. This research provides a new direction for the application of new technology in mathematics teaching.

There are still some shortcomings in the work. For example, the system has high requirements for hardware, and the application of the theories and the implementation of the models need certain software and programming language, which will be the direction for the follow-up research. In future, a simple mobile terminal teaching system will be developed and the teaching process will be optimized, making the model more simple. And "big data + AI" will be used to explore a more efficient teaching mode.

\section{Data Availability}

The data used to support the findings of this study are included within the article.

\section{Conflicts of Interest}

The author declares no conflicts of interest.

\section{References}

[1] J. Lee, "Integration of digital twin and deep learning in cyberphysical systems: towards," Smart Manufacturing, vol. 38, no. 8, pp. 901-910, 2020.

[2] J. Vrana, "Nde 4.0: digital twin, semantics, interfaces, networking, feedback," New Markets and Integration into the Industrial Internet of Things, vol. 78, no. 1, pp. 835-851, 2020.

[3] S. Agostinelli, F. Cumo, G. Guidi, and C. Tomazzoli, "Cyberphysical systems improving building energy management: digital twin and artificial intelligence," Energies, vol. 14, no. 8, p. 2338, 2021.

[4] Q. Qi and F. Tao, "Digital twin and big data towards smart manufacturing and industry 4.0: 360 degree comparison," IEEE Access, vol. 6, no. 5, pp. 3585-3593, 2018.

[5] C. Zhuang, J. Liu, and H. Xiong, "Digital twin-based smart production management and control framework for the complex product assembly shop-floor," International Journal of Advanced Manufacturing Technology, vol. 96, no. 1, pp. 1149-1163, 2018.

[6] Z. H. Lv, "Virtual reality in the context of internet of things," Neural Computing \& Applications, vol. 32, no. 2, pp. 9593-9602, 2019.

[7] P. O. Skobelev, I. V. Mayorov, E. V. Simonova et al., "Development of models and methods for creating a digital twin of plant within the cyber-physical system for precision farming management," Journal of Physics: Conference Series, vol. 1703, no. 1, pp. 27-29, 2020.

[8] P. C. Lopez, I. A. Udugama, S. T. Thomsen et al., "Towards a digital twin: a hybrid data-driven and mechanistic digital shadow to forecast the evolution of lignocellulosic fermentation," Biofuels, Bioproducts and Biorefining, vol. 14, no. 5, pp. 231-232, 2020.

[9] S. Chen, T. Wang, X. Li, Z. Liu, and D. Wu, "Research on the improvement of teachers' teaching ability based on machine learning and digital twin technology," Journal of Intelligent and Fuzzy Systems, vol. 40, no. 1, pp. 1-12, 2020.

[10] Y. Wu, J. Shang, and F. Xue, "RegARD: symmetry-based coarse registration of smartphone's colorful point clouds with CAD drawings for low-cost digital twin buildings," Remote Sensing, vol. 13, no. 10, p. 1882, 2021.

[11] A. Palade, C. Cabrera, F. Li, G. White, M. A. Razzaque, and S. Clarke, "Middleware for internet of things: an evaluation in a small-scale IoT environment," Journal of Reliable Intelligent Environments, vol. 4, no. 2, pp. 3-23, 2018.

[12] D. Daniel, C. Y. Le, K. Dmitry, L. Perrin, J. Großschädl, and A. Biryukov, "Triathlon of lightweight block ciphers for the internet of things," Journal of Cryptographic Engineering, vol. 14, no. 9, pp. 1-20, 2018.

[13] J. H. Pikul and H. Ning, "Powering the internet of things," Joule, vol. 2, no. 6, pp. 1036-1038, 2018.

[14] E. Bonham, K. Mcmaster, E. Thomson et al., "Designing and integrating a digital thread system for customized additive manufacturing in multi-partner kayak production," Systems, vol. 8 , no. 4 , p. $43,2020$. 
[15] P. D. Urbina Coronado, R. Lynn, W. Louhichi, M. Parto, E. Wescoat, and T. Kurfess, "Part data integration in the Shop Floor Digital Twin: mobile and cloud technologies to enable a manufacturing execution system," Journal of Manufacturing Systems, vol. 48, no. 3, pp. 25-33, 2018.

[16] A. H. Sodhro, S. Pirbhulal, and A. K. Sangaiah, "Convergence of IoT and product lifecycle management in medical health care," Future Generation Computer Systems, vol. 86, no. 9, pp. 380-391, 2018.

[17] L. Broche, R. S. Zamora, and R. Rodriguez, "Digital Twin: an option for the integrated design of upper limb robotic exoskeletons for rehabilitation tasks," Journal of Engineering and Applied Sciences, vol. 16, no. 6, pp. 423-424, 2021.

[18] K. N. Anyfantis, "An abstract approach toward the structural digital twin of ship hulls: a numerical study applied to a box girder geometry," Proceedings of the Institution of Mechanical Engineers-Part M: Journal of Engineering for the Maritime Environment, vol. 235, no. 3, pp. 146-147, 2021.

[19] R. Wilson, P. H. J. Mercier, B. Patarachao, and A. Navarra, "Partial least squares regression of oil sands processing variables within discrete event simulation digital twin," Minerals, vol. 11 , no. 7, p. $689,2021$.

[20] A. Francisco, N. Mohammadi, and J. E. Taylor, "Smart city digital twin-enabled energy management: toward real-time urban building energy benchmarking," Journal of Management in Engineering, vol. 36, no. 2, pp. 1-11, 2020.

[21] V. Kuts, N. Cherezova, M. Sarkans, and T. Otto, "Digital Twin: industrial robot kinematic model integration to the virtual reality environment," Journal of Machine Engineering, vol. 20, no. 2, pp. 53-64, 2020.

[22] K. Sjostrand and L. S. Clemmensen, "A MATLAB toolbox for sparse statistical modeling," Journal of Statistical Software, vol. 84, no. 10, pp. 25-27, 2018.

[23] G. Silvia, H. P. Christian, and J. G. Nagy, "IR tools: a MATLAB package of iterative regularization methods and large-scale test problems," Numerical Algorithms, vol. 81, no. 1, pp. 773-811, 2018.

[24] C. Frishmuth, "Virtual reality," Pc Pilot, vol. 14, no. 120, pp. 48-51, 2019.

[25] M. S. Elbamby, C. Perfecto, M. Bennis, and K. Doppler, "Toward low-latency and ultra-reliable virtual reality," IEEE Network, vol. 32, no. 2, pp. 78-84, 2018.

[26] C. Anda, S. Medina, and K. W. Axhausen, "Synthesising digital twin travellers: individual travel demand from aggregated mobile phone data," Transportation Research Part C: Emerging Technologies, vol. 128, no. 1, pp. 118-121, 2021.

[27] H. C. Kim, Y. H. Son, J. Bae, and S. D. Noh, "A study on the digital twin visualization method for smart factory of dye processing industry," Journal of the Korean Institute of Industrial Engineers, vol. 47, no. 1, pp. 77-91, 2021.

[28] J. Vrana, "The core of the fourth revolutions: industrial internet of things, digital twin, and cyber-physical loops," Journal of Nondestructive Evaluation, vol. 40, no. 2, pp. 46-467, 2021.

[29] M. Rus-calafell, P. Garety, E. Sason, T. J. K. Craig, and L. R. Valmaggia, "Virtual reality in the assessment and treatment of psychosis: a systematic review of its utility, acceptability and effectiveness," Psychological Medicine, vol. 48, no. 3, pp. 1-2, 2018.

[30] M. Meissner, J. Pfeiffer, T. Pfeiffer, and H. Oppewal, "Combining virtual reality and mobile eye tracking to provide a naturalistic experimental environment for shopper research," Journal of Business Research, vol. 100, no. 6, pp. $445-458,2018$. 